\title{
Analysis of the equine ovarian structure during the first twelve months of life by three-dimensional internal structure microscopy
}

\author{
Mamiko ONO ${ }^{1) \#, ~ H i r o k i ~ A K U Z A W A ~ 2) \#, ~ Y a s u o ~ N A M B O ~}{ }^{3,8)}$, Yuuko HIRANO4), Junpei KIMURA ${ }^{5)}$, Satoko TAKEMOTO ${ }^{6}$, \\ Sakiko NAKAMURA ${ }^{6}$, Hideo YOKOTA $^{6}$, Ryutaro HIMENO ${ }^{6}$, Tohru HIGUCHI ${ }^{7}$, Tadatoshi OHTAKI ${ }^{1)}$ and \\ Shigehisa TSUMAGARI ${ }^{1) *}$ \\ ${ }^{1)}$ Department of Veterinary Medicine, College of Bioresource Sciences, Nihon University, Fujisawa, Kanagawa 252-0880, Japan \\ ${ }^{2)}$ Northernfarm, Koka, Shiga 529-1812, Japan \\ ${ }^{3)}$ Hidaka Training and Research Center, Japan Racing Association, 535-13 Aza-Nishicha, Urakawa-cho, Urakawa-gun, Hokkaido \\ 057-0171, Japan \\ 4) Obihiro University of Agriculture and Veterinary Medicine, Obihiro, Hokkaido, 080-8555, Japan \\ ${ }^{5)}$ College of Veterinary Medicine, Seoul National University, Seoul 151-742, Korea \\ ${ }^{6)}$ RIKEN, Wako, Saitama 351-0198, Japan \\ ${ }^{7)}$ Hidaka Agriculture Mutual Aid Association, Hidaka, Hokkaido 059-3105, Japan \\ ${ }^{8)}$ Present address: Obihiro University of Agriculture and Veterinary Medicine, Obihiro, Hokkaido 080-8555, Japan
}

(Received 14 October 2014/Accepted 29 June 2015/Published online in J-STAGE 18 July 2015)

ABSTRACT. A three-dimensional internal structure microscopy (3D-ISM) can clarify the anatomical arrangement of internal structures of equine ovaries. In this study, morphological changes of the equine ovary over the first 12 months of life were investigated by 3D-ISM in 59 fillies and by histological analysis in 2 fillies. The weight and volume of the paired ovaries initially decreased from 0 to 1 months to 2 to 3 months of age and then significantly increased at 8 to 12 months of age. The ovulation fossa was first observed around the 3rd month and became evident after the 6 th month. The number of follicles with a diameter of $\geq 10 \mathrm{~mm}$ and the diameter of the largest follicle increased gradually after 6 months of age. On a volume basis, the medulla accounted for nearly $90 \%$ of the whole ovary at 0 to 1 months of age, but significantly decreased from 2 to 3 months of age. The volume of the cortex increased progressively after birth and reached approximately $60 \%$ of the total volume at 8 to 12 months of age. This significant development of the cortex coincided with the increased number and size of large follicles observed from 6 months of age. These results suggest that the development of the cortex plays a role in the maturation of the follicles and the equine ovary undergoes substantial morphological changes postnatally until puberty.

KEY WORDS: filly, morphology, ovary, prepuberty, three-dimensional internal structure microscopy

doi: 10.1292/jvms.14-0539; J. Vet. Med. Sci. 77(12): 1599-1603, 2015

In comparison with those of other mammalian species, the ovaries of the mare are structurally unique. First, they are remarkably large and can measure as much as 5 to $8 \mathrm{~cm}$ along the major axis and 2 to $4 \mathrm{~cm}$ along the minor axis [25]. Their shape changes considerably with the estrous cycle, as the follicles may grow up to 4 to $5 \mathrm{~cm}$ in diameter in light breed mares $[2,5,7,21]$. Second, the location of cortex and medulla is inverted. The follicles and corpus luteum (CL) are within the cortical zone. They are enclosed within a dense, richly vascularized connective tissue casing that corresponds to the medulla of the ovary of other species $[5,7,22]$. This reversed structure is only seen in Equidae species, the ninebanded armadillo (Dasypus novemcinctus) [6] and the cuis (Galea musteloides) [25]. Finally, ovulation only occurs at the ovulation fossa in the mare [22, 28].

\footnotetext{
*Correspondence to: Tsumagari, S., Department of Veterinary Medicine, College of Bioresource Sciences, Nihon University, Fujisawa, Kanagawa 252-0880, Japan. e-mail: tumagar@brs.nihon-u.ac.jp \#These authors contributed equally to this work.

(C)2015 The Japanese Society of Veterinary Science

This is an open-access article distributed under the terms of the Creative Commons Attribution Non-Commercial No Derivatives (by-nc-nd) License $<$ http://creativecommons.org/licenses/by-nc-nd/3.0/>.
}

The equine fetal gonads are ellipsoidal in both males and females, and interstitial cells account for more than twothirds of the fetal ovary producing the maternal estrogen precursor [1,9-11]. The marked enlargement of the gonads (ovaries or testes) reached a peak around day 250 of gestation and was caused by hypertrophy and hypoplasia of interstitial cells. The fetal gonads later had begun to regress, and degenerative changes were apparent in the interstitial cells $[1,11,23]$. At birth, they are reduced to one-tenth of their greatest fetal size $[5,14]$, but the reversal of the cortex and medulla and formation of the ovulation fossa have not yet occurred. The ovulation fossa develops at 5 to 7 months of age $[8,14,24]$, and the ovaries reach their structural maturity at around the beginning of puberty [8]. Thus, the structurally unique equine ovaries undergo extensive morphological changes from the fetal stage until puberty.

Recently, Kimura et al. [15] reported detailed analysis of the internal anatomical structure of the equine ovary using three-dimensional internal structure microscopy (3D-ISM), which consists of a computer-controlled slicer and a CCD camera. In addition, three-dimensional reconstructed images of the equine ovary from more than 1,000 sliced images can provide quantifiable information of follicles and CL and reveal the population of the follicles as small as $1 \mathrm{~mm}^{3}$ in 
volume [12, 16, 17]. The morphology of prepubertal mare ovary has been studied through several techniques; macroscopic morphology [8, 18, 26], histology [8, 24] and ultrasonography $[18,20]$. However, it is difficult to evaluate the exact number of small follicles by those techniques, because of those limited resolution.

In the present study, the observation of the internal structure of the prepubertal mare ovary by 3D-ISM was applied for the first time to understand their changes over the first 12 months after birth.

\section{MATERIALS AND METHODS}

Samples: Ovaries $(\mathrm{n}=122)$ from 61 nutritionally wellmanaged Thoroughbred fillies (0- to 12-month-old) born between February and May were used in the study. All fillies were necropsied at NOSAI Hidaka (Hidaka, Japan) to investigate the cause of their death. Most fillies were dead by the cause of weakness, pneumonia, stomach ulcer and bone fracture, regardless of any reproductive disorder.

The study protocol was reviewed and approved by the animal care and ethics committees in Equine Research Institute, Japan Racing Association. Ovaries were weighted, then were dissected out and fixed in 10\% formalin until use. Fifty-nine paired ovaries were used for 3D-ISM and classified into five age groups: 0 to $1(n=32) ; 2$ to $3(n=8) ; 4$ to $5(n=6) ; 6$ to 7 $(n=9)$; and 8 to 12 months of age $(n=4)$. Two paired ovaries from 0 - and 142-day-old fillies were processed for histological evaluation.

Internal structure analysis of the equine ovary by 3DISM: Three-dimensional images were obtained by 3D-ISM technique reported by Kimura et al. [15]. Briefly, ovaries were dipped into an embedding solution (OCT compound; Sakura Finetek Japan Co., Ltd., Tokyo, Japan) within a metallic case and were frozen at $-80^{\circ} \mathrm{C}$. The frozen-embedded ovaries were then removed from the case and sliced serially using a computer-controlled slicer (MSS-225f, Toshiba Machine Co., Ltd., Shizuoka, Japan). Images of each cut surface were recorded by a CCD camera (DXC-930, SONY, Tokyo, Japan) and stored in digital format. The three-dimensional reconstruction was performed by the full-colored ray-casting volume-rendering method using Voxical Viewer ${ }^{\mathrm{TM}}$ (Toshiba Machine Co., Ltd.). The volume of the ovary was calculated from the reconstructed 3D image as previously described by Hirano et al [12]. The cortex and medulla within the ovary were extracted by the region extraction algorithm based on mean shift and k-means clustering (Fig. 1). The mean shift algorithm was used to reduce the color depth by grouping the regions with similar colors. Then, the image was partitioned into three classes, the background, cortex (white) and other structures (gray), by the k-means method. Since the gray region contained both the follicles and medulla, the medulla was determined by subtracting the information of follicles extracted manually from the gray region. The follicles within the gray region were regrouped with the cortex. The volume of cortex and medulla was calculated as a mean value of two randomly selected paired ovaries from each age group.

Histology: According to the conventional methods, fixed ovaries were embedded in paraffin, sectioned in 3- $\mu$ m thickness and stained with hematoxylin and eosin for microscopic evaluation.

Statistics: Statistical analysis was performed using JMP software ver. 8.02 (SAS Institute, Tokyo, Japan). TukeyKramer test was used for comparison among the five age groups. Spearman's rank correlation coefficient was used to assess the relationship between two variables. A level of significance less than 0.05 was considered statistically significant. All data were expressed as means \pm standard error of the mean (SEM).

\section{RESULTS}

Morphology of developing ovaries and follicles: The combined weight and volume of the paired ovaries, the diameter of the largest follicle and the number of follicles are shown in Table 1 . The combined weight and volume of paired ovary decreased from 0 to 1 months to 2 to 3 months of age and then slightly increased at 6 to 7 months of age. The weight and volume were significantly higher at 8 to 12 months of age compared to all other age groups $(P<0.05$ vs. 0 to 1 months of age; $P<0.01$ vs. the other age groups). A significantly strong positive correlation was observed between the volume and the weight of the ovaries $(\rho=0.96, P<0.0001)$. The number of follicles with a diameter of $<5 \mathrm{~mm}$ was most frequent in all age groups and was especially in 6 to 7 months of age. But, there was no statistically significant age-dependent tendency. The follicles with a diameter of $\geq 10 \mathrm{~mm}$ were not observed in fillies' ovaries under 4 months of age, but their numbers slightly increased at 6 to 7 months of age and significantly increased at 8 to 12 months of age compared to all other age groups $(P<0.01)$. The diameter of the largest follicle slightly increased at 4 to 5 months of age and significantly increased at 8 to 12 months of age compared to all other age groups $(P<0.01)$.

Comparison of ovarian 3D-ISM cross-sections and histological findings: Cross-sections of a 0-day-old ovary obtained by 3D-ISM showed a pale yellow region at the depressed border, and the inside of the ovary was filled with dark brown-colored structures. Histologically, the pale yellow region consisted of loose connective tissue, while the dark brown region contained blood vessels and interstitial cells. On the other hand, in cross-sections of a 142-day-old ovary (approximately 5 months old), the dark brown layer was the outside of the ovary, which consisted of blood vessels and large brown-colored cells in the histological findings. Inside the ovary was a pale yellow region, and this region contained secondary follicles and antral follicles in the histological findings. The large brown cells observed in the outer layer were likely interstitial cells or debris which was phagocytized by macrophage as previously reported by Ginther [8]. These findings indicated that the yellow pale region corresponded to the cortex, and the dark brown region was the medulla.

Internal structure of the developing ovary: The gross appearance and 3D-ISM cross-sections of the ovary are shown chronologically in Fig. 2. At 0- to 2-month-old ovary (Fig. $2 \mathrm{~A}$ ), almost the entire ovary was filled with dark-colored 
A

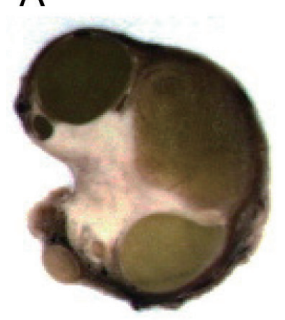

B

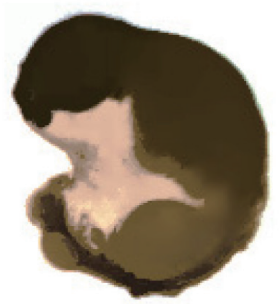

C

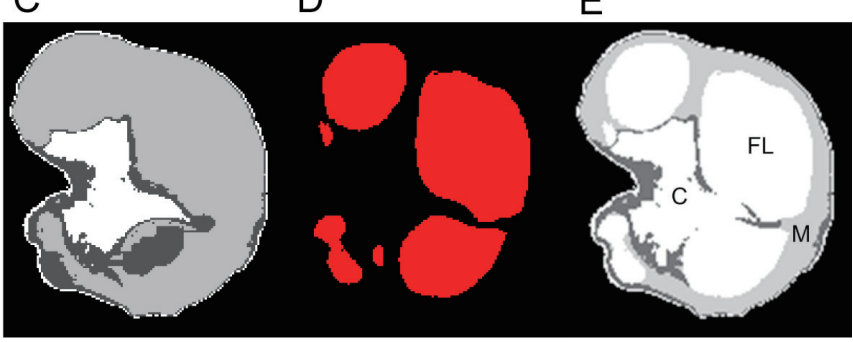

Fig.1. Extraction of the cortex and medulla of the equine ovary (341 days old) A: Original image. Inside the ovary was a pale yellow region, and the outer layer of the ovary was a dark brown region. B: Regions with similar colors were grouped by the mean shift method. C: The image was divided into three classes, the background, cortex (white) and medulla (gray), by the kmeans method. D: Regions corresponding to the follicles (red) were extracted from the original image. E: A composite image of $\mathrm{C}$ and $\mathrm{D}$. The follicles detected within the medulla were regrouped with the cortex. FL, follicle; C, cortex; M, medulla.

Table 1. Morphology of the ovaries: weight, number of follicles and diameter of largest follicle

\begin{tabular}{|c|c|c|c|c|c|c|c|c|c|c|c|}
\hline \multirow{2}{*}{$\begin{array}{l}\text { Group of fillies } \\
\text { (months of age) }\end{array}$} & \multirow{2}{*}{$\mathrm{n}$} & \multirow{2}{*}{$\begin{array}{l}\text { Weight of ovary } \\
\text { (g) }\end{array}$} & \multirow{2}{*}{$\begin{array}{l}\text { Volume of } \\
\text { ovary }\left(\mathrm{cm}^{3}\right)\end{array}$} & \multicolumn{7}{|c|}{ Number of follicles } & \multirow{2}{*}{$\begin{array}{l}\text { Diameter of largest } \\
\text { follicle }(\mathrm{mm})\end{array}$} \\
\hline & & & & $<5 \mathrm{~mm}$ & $5-10 \mathrm{~mm}$ & $10-15 \mathrm{~mm}$ & $15-20 \mathrm{~mm}$ & $20-25 \mathrm{~mm}$ & $25-30 \mathrm{~mm}$ & $\geq 30 \mathrm{~mm}$ & \\
\hline $0-1$ & 32 & $29.6 \pm 3.9^{\mathrm{a}}$ & $28.1 \pm 3.7^{\mathrm{a}}$ & $27.7 \pm 6.0$ & $2.3 \pm 0.6$ & $0.0 \pm 0.0^{\mathrm{A}}$ & $0.0 \pm 0.0^{\mathrm{A}}$ & $0.0 \pm 0.0^{\mathrm{A}}$ & $0.0 \pm 0.0^{\mathrm{A}}$ & $0.0 \pm 0.0^{\mathrm{A}}$ & $5.3 \pm 0.4^{\mathrm{A}}$ \\
\hline $2-3$ & 8 & $11.0 \pm 0.6^{\mathrm{A}}$ & $10.4 \pm 0.5^{\mathrm{A}}$ & $21.0 \pm 4.3$ & $2.0 \pm 1.2$ & $0.0 \pm 0.0^{\mathrm{A}}$ & $0.0 \pm 0.0^{\mathrm{A}}$ & $0.0 \pm 0.0^{\mathrm{a}}$ & $0.0 \pm 0.0^{\mathrm{A}}$ & $0.0 \pm 0.0^{\mathrm{A}}$ & $5.0 \pm 0.6^{\mathrm{A}}$ \\
\hline $4-5$ & 6 & $10.7 \pm 1.5^{\mathrm{A}}$ & $11.9 \pm 1.6^{\mathrm{A}}$ & $9.2 \pm 2.9$ & $1.2 \pm 0.7$ & $0.0 \pm 0.0^{\mathrm{A}}$ & $0.0 \pm 0.0^{\mathrm{A}}$ & $0.2 \pm 0.2$ & $0.0 \pm 0.0^{\mathrm{a}}$ & $0.0 \pm 0.0^{\mathrm{A}}$ & $7.4 \pm 2.7^{\mathrm{A}}$ \\
\hline $6-7$ & 9 & $16.0 \pm 1.7^{\mathrm{A}}$ & $17.3 \pm 2.2^{\mathrm{A}}$ & $47.9 \pm 7.6$ & $6.3 \pm 2.4$ & $0.8 \pm 0.4^{\mathrm{a}}$ & $0.0 \pm 0.0^{\mathrm{A}}$ & $0.0 \pm 0.0^{\mathrm{a}}$ & $0.0 \pm 0.0^{\mathrm{a}}$ & $0.0 \pm 0.0^{\mathrm{A}}$ & $8.2 \pm 1.2^{\mathrm{A}}$ \\
\hline $8-12$ & 4 & $63.3 \pm 12.7 \mathrm{~b}, \mathrm{~B}$ & $55.2 \pm 15.2 \mathrm{~b}, \mathrm{~B}$ & $19.3 \pm 3.4$ & $5.5 \pm 1.6$ & $2.5 \pm 1.0^{\mathrm{b}, \mathrm{B}}$ & $1.5 \pm 1.0^{\mathrm{B}}$ & $0.5 \pm 0.5^{b, B}$ & $0.3 \pm 0.3^{\mathrm{b}, \mathrm{B}}$ & $0.5 \pm 0.3^{\text {В }}$ & $21.0 \pm 6.0^{\mathrm{B}}$ \\
\hline
\end{tabular}

Values are mean \pm SEM. Values with different superscripts within each row differ significantly. Capital letters indicate diferences at $P<0.01$, and small letters indicate differences at $P<0.05$. Weight and volume of ovary and number of follicles are the total of paired ovary.

A
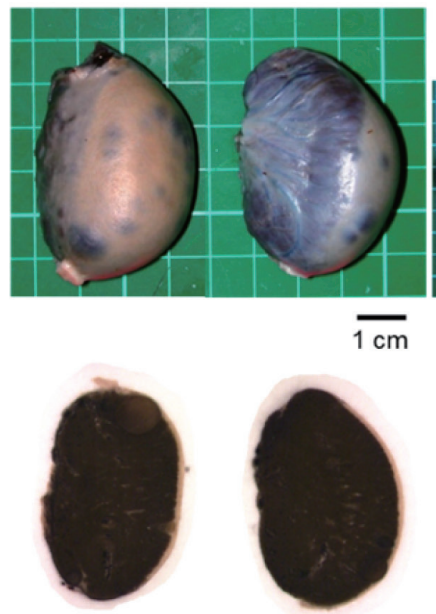

$\mathrm{L}$

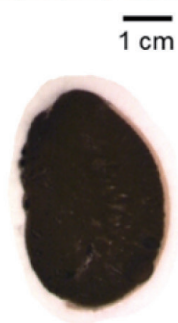

$\mathrm{R}$
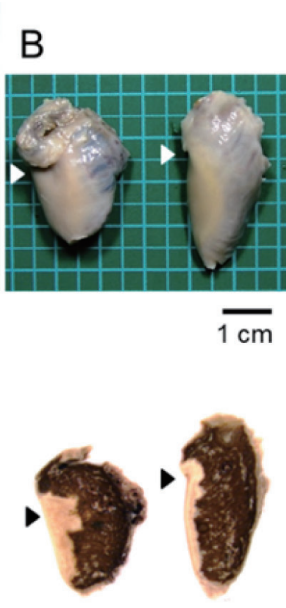

$\mathrm{L}$

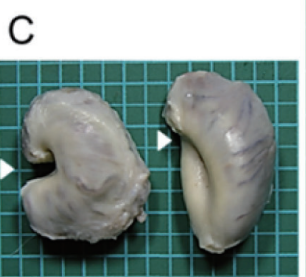

$\overline{1 \mathrm{~cm}}$

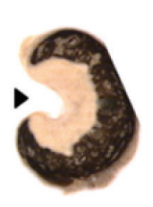

$\mathrm{L}$
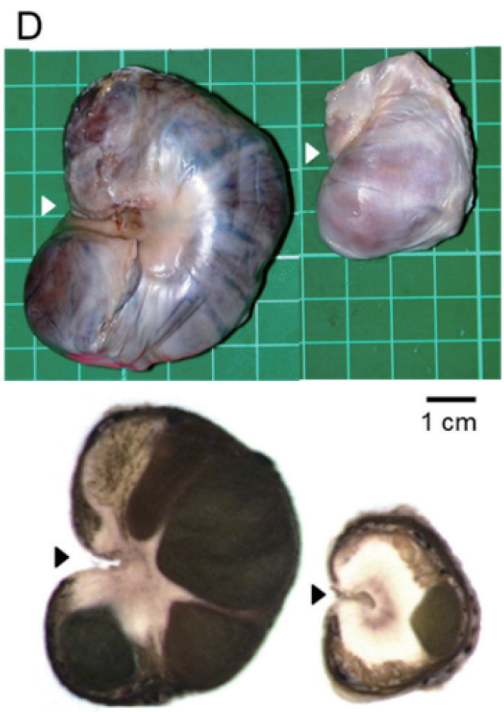

L
$\mathrm{R}$

Fig. 2. Morphological changes of the equine ovary over the first 12 months of life. A: 1-day-old ovaries (approximately 0 month old). Almost the entire ovary was filled with the medulla, and a cortex was observed as a very thin region around the medulla. B: 110-dayold ovaries (approximately 3 months old). The medullar structures became evident on the surface of the ovary, and formation of the ovulation fossa (arrowhead) was first recognized at around 3 months of age. C: 211 -day-old ovaries (approximately 7 months old). Formation of the ovulation fossa was clearly seen after 6 months of age. D: 351-day-old ovaries (approximately 11 months old). The ovary was occupied largely by follicles, which were surrounded by vessels.

structures (the medulla), and a cortex was observed as a very thin, light-colored layer around the medulla. With age, the proportion of the medulla decreased, while that of the cortex increased (Fig. 2A-2D). From 3 months of age, the medullar structures became located just under the surface of the ovary, except at the site of formation of the ovulation fossa, 
while invagination of the cortex was observed. As these tissue rearrangements progressed, the two poles of the ovary became closer to each other, and the ovulation fossa was eventually formed. Reversal of the cortex and medulla was also observed progressively with age. Detection rates of the ovulation fossa in the ovaries of 0 to 1 months, 2 to 3 months, 4 to 5 months, 6 to 7 months and 8 to 12 months of age were $1.6 \%(1 / 64), 37.5 \%(6 / 16), 66.7 \%(8 / 12), 100 \%(18 / 18)$ and $100 \%(8 / 8)$, respectively. The formation of the ovulation fossa was seen as a clear structure after 6 months of age. In the 8- to 12-month-old ovary, the ovaries were occupied largely by follicles, which were surrounded by vessels.

The volume of the cortex and medulla: The volume of the cortex and medulla and the cortex-to-ovary ratio of two randomly selected paired ovaries from each age group are shown in Fig. 3. The volume of the cortex was $\leq 3 \mathrm{~cm}^{3}$ before 8 months of age, but increased significantly at 8 to 12 months of age $(P<0.05)$. The volume of the medulla decreased significantly at 2 to 3 months of age compared to 0 to 1 months of age, but increased again at 8 to 12 months of age. The volume of the cortex showed strong positive correlations with the diameter of the largest follicle $(\rho=0.88$, $P<0.0001)$ as well as with the number of follicles with a diameter of $\geq 10 \mathrm{~mm}(\rho=0.75, P=0.0001)$. The cortex-to-ovary ratio was $9.1 \pm 2.0 \%$ at 0 to 1 months of age, indicating that the medulla accounted for a large part of the ovary at this age. The percentage of the cortex increased significantly 2 to 3 months compared to 0 to 1 months of age $(P<0.001)$ and reached $60.0 \pm 6.9 \%$ at 8 to 12 months of age.

\section{DISCUSSION}

3D-ISM can clarify the anatomical arrangement of internal structures of equine ovaries and also promptly detect all follicles larger than $1 \mathrm{~mm}$ in diameter [14, 19]. In this study, the number of follicles with a diameter of 1 to $4 \mathrm{~mm}$ was most frequent in all age groups, and the follicles with a diameter of $\geq 10 \mathrm{~mm}$ were not observed until 4 months of age. This study revealed the changes in the number of smaller follicles in detail in comparison with previous studies using macroscopic morphology $[18,26]$.

The diameter of the largest follicle slightly increased at 6 to 7 months of age and significantly increased at 8 to 12 months of age compared to all other age groups $(P<0.01)$. Puberty in mare starts generally at around the 18th month, but it may occur as early as the 12th month at the beginning of a breeding season, if the animal was born in spring or is nutritionally in good condition $[3,4,27]$. Therefore, the increases in the number and size of the large follicles observed at 8 to 12 months of age are likely the signs of the maturation process toward the first estrus.

We also found that the weight and volume of the ovaries decreased from 0 to 1 months to 2 to 3 months of age, although they increased again at 8 to 12 months of age. These increases were observed in parallel with the increases in the number and size of the large follicles and were consistent with a previous study that reported an increase in ovarian weight at 9 to 12 months old $[18,26]$.
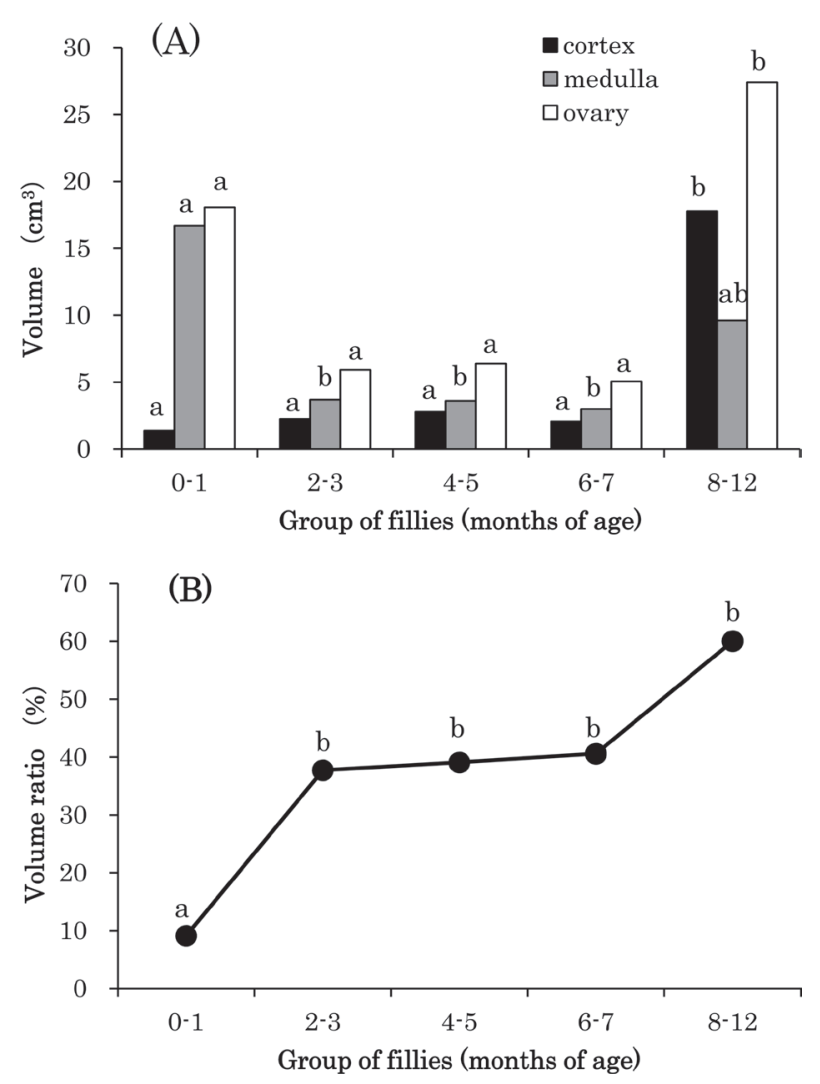

Fig. 3. Volume of the cortex, medulla (A) and ovary and cortex-toovary ratio $(B)$ at 0 to $1(n=2), 2$ to $3(n=2), 4$ to $5(n=2), 6$ to 7 $(n=2)$ and 8 to $12(n=2)$ months of age. Different letters indicate significant differences $(P<0.05)$ between the same tissues.

In comparison of ovarian 3D-ISM cross-sections and histological findings, the yellow pale region corresponded to the cortex, and the dark brown region was the medulla. For the first 2 months of life, almost the entire space of the ovary was filled with the medullar structures, which contained primarily interstitial cells by histological findings, and a cortex was observed as a minimal covering around the medulla. Then, the medulla decreased in volume. According to the morphological study of gonadal interstitial cells in equine fetus, they underwent progressive hypertrophy to reach a maximum size around 250 days of gestation, and subsequent degenerative changes resulted in a rapid decrease in the volume density and size of the interstitial cells $[11,23]$. Since the interstitial spaces in the equine testes seemed to decrease age-dependently after birth [13], it is considered that similar decrease occurs also in the equine ovaries $[11,23]$. In our present observation by 3D-ISM, the medullar structures started to develop at the surface of the ovary, except where the ovulation fossa would be formed, and the cortex started to invaginate to form an ovulation fossa. At around the 3 months of age, reversal of the cortex and medulla progressed. The ovulation fossa was first recognizable at around the 3 months of age and became evident at the 6 months of age. This timing was consistent with previous reports $[8,24]$ and 
suggests that the formation of the ovulation fossa precedes the development of large follicles.

The volume of the cortex and the cortex-to-ovary ratio increased progressively after birth, and their increases were significant at 8 to 12 months of age. The volume of the cortex was strongly correlated with the number and size of large follicles, indicating that the increase in cortex volume occurs coincidently with follicular development toward puberty. On the contrary, the volume of the medulla showed a significant decrease from 0 to 1 months to 2 to 3 months of age due to progressive degeneration of interstitial cells as indicated by 3D-ISM and histological findings. The volume of the medulla increased again at 8 to 12 months of age, because the blood vessels were well developed to support the growing number and size of follicles.

In summary, the use of 3D-ISM provided morphological understanding of the ovaries of fillies by revealing detailed internal structures and accurately estimating their sizes. The present study suggests the following sequence of events during the postnatal development of the equine ovary. After birth, the size of the ovary initially decreases due to medullar regression associated with the degeneration of interstitial cells. At around the 3rd month, formation of the ovulation fossa as well as reversal of the medulla and cortex starts. These events are followed by the development of large follicles at around 6 to 7 months of age. These results suggest that the development of the cortex plays a role in the maturation of the follicles and that the equine ovary undergoes substantial morphological changes postnatally until puberty.

\section{REFERENCES}

1. Allen, W. R. 2001. Fetomaternal interactions and influences during equine pregnancy. Reproduction 121: 513-527. [Medline] [CrossRef]

2. Arthur, G. H. 1958. An analysis of the reproductive function of mares based on post-mortem examination. Vet. Rec. 70: 682-686.

3. Aurich, C. 2011. Reproductive cycles of horses. Anim. Reprod. Sci. 124: 220-228. [Medline] [CrossRef]

4. Brown-Douglas, C. G., Firth, E. C., Parkinson, T. J. and Fennessy, P. F. 2004. Onset of puberty in pasture-raised Thoroughbreds born in southern hemisphere spring and autumn. Equine Vet. J. 36: 499-504. [Medline] [CrossRef]

5. Dyce, K. M., Sack, W. O. and Wensing, C. J. G. 2009. The pelvis and reproductive organs of the horse. pp. 563-585. In: Textbook of Veterinary Anatomy, 4th ed., Saunders, St. Louis.

6. Enders, A. C. and Buchanan, G. D. 1959. The reproductive tract of the female nine-banded armadillo. Tex. Rep. Biol. Med. 17: 323-340. [Medline]

7. Ginther, O. J. 1992. Reproductive anatomy. pp. 1-40. In: Reproductive Biology of the Mare: Basic and Applied Aspects, 2nd ed., Equiservices Publishing, Cross Plains.

8. Ginther, O. J. 1992. Parturition, puerperium and puberty. pp. 457-498. In: Reproductive Biology of the Mare: Basic and Applied Aspects, 2nd ed., Equiservices Publishing, Cross Plains.

9. González-Angulo, A., Hernández-Jáuregui, P. and MárquezMonter, H. 1971. Fine structure of gonads of the fetus of the horse (Equus caballus). Am. J. Vet. Res. 32: 1665-1676. [Medline]

10. González-Angulo, A., Hernández-Jáuregui, P. and Martínez-Zedilo,
G. 1975. Fine structure of the gonads of the horse and its functional implications. J. Reprod. Fertil. Suppl. 23: 563-567. [Medline]

11. Hay, M. F. and Allen, W. R. 1975. An ultrastructural and histochemical study of the interstitial cells in the gonads of the fetal horse. J. Reprod. Fertil. Suppl. 23: 557-561. [Medline]

12. Hirano, Y., Kimura, J., Nambo, Y., Yokota, H., Nakamura, S., Takemoto, S., Himeno, R., Mishima, T., Matsui, M. and Miyake, Y. I. 2009. Population of follicles and luteal structures during the oestrous cycle of mares detected by three-dimensional internal structure microscopy. Anat. Histol. Embryol. 38: 214-218. [Medline] [CrossRef]

13. Hondo, E., Murabayashi, H., Hoshiba, H., Kitamura, N., Yamanouchi, K., Nambo, Y., Kobayashi, T., Kurohmaru, M. and Yamada, J. 1998. Morphological studies on testicular development in the horse. J. Reprod. Dev. 44: 377-383. [CrossRef]

14. Kainer, R. A. 1993. Reproductive organs of the mare. pp. 5-19. In: Equine Reproduction. (McKinnon, A. O. and Voss, J. L. eds.), Lea \& Febiger, Philadelphia.

15. Kimura, J., Tsukise, A., Yokota, H., Nambo, Y. and Higuchi, T. 2001. The application of three-dimensional internal structure microscopy in the observation of mare ovary. Anat. Histol. Embryol. 30: 309-312. [Medline] [CrossRef]

16. Kimura, J., Hirano, Y., Takemoto, S., Nambo, Y., Ishinazaka, T., Himeno, R., Mishima, T., Tsumagari, S. and Yokota, H. 2005. Three-dimensional reconstruction of the equine ovary. Anat. Histol. Embryol. 34: 48-51. [Medline] [CrossRef]

17. Kimura, J., Kakusho, N., Yamazawa, K., Hirano, Y., Nambo, Y., Yokota, H. and Himeno, R. 2009. Stereolithographic biomodeling of equine ovary based on 3D serial digitizing device. J. Vet. Sci. 10: 161-163. [Medline] [CrossRef]

18. Mlodawska, W. and Okolski, A. 2009. Morphological characterization and meiotic competence of oocytes collected from filly ovaries. Theriogenology 71: 1046-1053. [Medline] [CrossRef]

19. Nogueira, G. P. and Ginther, J. 2000. Dynamics of follicle populations and gonadotropin concentrations in fillies age two to ten months. Equine Vet. J. 32: 482-488. [Medline] [CrossRef]

20. Nogueira, G. P. 2004. Follicle profile and plasma gonadotropin concentration in pubertal female ponies. Braz. J. Med. Biol. Res. 37: 913-922. [Medline] [CrossRef]

21. Pierson, R. A. and Ginther, O. J. 1985. Ultrasonic evaluation of the preovulatory follicle in the mare. Theriogenology $\mathbf{2 4}$ : 359-368. [Medline] [CrossRef]

22. Stabenfeldt, G. H., Hughes, J. P., Evans, J. W. and Geschwind, I. I. 1975. Unique aspects of the reproductive cycle of the mare. $J$. Reprod. Fertil. Suppl. 23: 155-160. [Medline]

23. Tsunoda, N., Machida, N., Nagata, S., Nagamine, N., Nambo, Y., Oikawa, M., Taniyama, H., Watanabe, G. and Taya, K. 1996. A morphometric study of interstitial cells in equine fetal gonads. $J$. Reprod. Dev. 42: j91-j95. [CrossRef]

24. Walt, M. L., Stabenfeldt, G. H., Hughes, J. P., Neely, D. P. and Bradbury, R. 1979. Development of the equine ovary and ovulation fossa. J. Reprod. Fertil. Suppl. 27: 471-477. [Medline]

25. Weir, B. J. and Rowlands, I. W. 1974. Functional anatomy of the hystricomorph ovary. Symp. Zool. Soc. Lond. 34: 303-332.

26. Wesson, J. A. and Ginther, O. J. 1981. Influence of season and age on reproductive activity in pony mares on the basis of a slaughterhouse survey. J. Anim. Sci. 52: 119-129. [Medline]

27. Wesson, J. A. and Ginther, O. J. 1981. Puberty in the female pony: reproductive behavior, ovulation, and plasma gonadotropin concentrations. Biol. Reprod. 24: 977-986. [Medline] [CrossRef]

28. Witherspoon, D. M. and Talbot, R. B. 1970. Ovulation site in the mare. J. Am. Vet. Med. Assoc. 157: 1452-1459. [Medline] 